\title{
Clinico-epidemiological features and response in childhood acute Iymphoblastic leukemia at regional cancer center of Northeast India
}

\author{
Bhargab Jyoti Saikia, Partha Sarathi Roy, Gaurav Kumar, Rakesh Kumar Mishra,Anupam Sarma'
}

\begin{abstract}
Introduction: Acute lymphoblastic leukemia (ALL) comprises 19.3\% of all childhood cancers in Northeast India. Methods:We analyzed clinicoepidemiological features and early response to the treatment of all the cases of childhood ALL (age $<15$ years) diagnosed and treated at Dr. B Borooah Cancer Institute over I year. Results: Of 52 eligible cases, $69 \%$ were male (male:female ratio of 2.2:I) and the mean age was 7.1 years. Thirty-three children (63\%) had baseline white blood cell count $\geq 20 \times 10^{9} / \mathrm{L}$. Precursor B-cell was most the common subtype seen in $61 \%$ of children. Seven cases (I4\%) had high-risk (HR) cytogenetics, with $t(9,22)$ being the most common one. Male sex and HR cytogenetics were significantly associated with poor early responses. Conclusion: ALL is a common childhood malignancy with high cure rates. However, poor socioeconomic status and the presence of higher proportions of disease-related factors lead to poor outcome in this part of the country.

Key words: Cytogenetics, early response, minimum residual disease, risk stratification
\end{abstract}

\section{Introduction}

Leukemia constitutes about $30 \%-50 \%$ of all childhood cancers globally. ${ }^{[1-4]}$ In India, the proportion of children with acute leukemia ranged from $26.7 \%$ to $52.3 \%$ of all childhood cancers. ${ }^{[5-7]}$ However, in Northeast India, acute leukemia constitutes around $27 \%$ of all childhood cancers with acute lymphoblastic leukemia (ALL) being the most common, comprising $19.3 \%$ of all childhood cancers. ${ }^{[8]}$

We sought to provide a comprehensive assessment of clinicoepidemiological features and early response to the treatment of childhood ALL diagnosed and treated at our institute over a period of 1 year.

\section{Methods}

In this retrospective study, we analyzed all the cases of childhood ALL diagnosed and treated at Dr. B Borooah Cancer Institute, Guwahati, from January 1, 2018, to December 31, 2018. The study received the Institutional Ethics Committee approval.

All newly diagnosed children aged $<15$ years with flow cytometry-based diagnosed cases of ALL were included in the study. Children with relapsed ALL at presentation, referred patients from other centers for continuing part of their treatment, patients not received any treatment after confirmation of the diagnosis, and patients who failed to undergo complete diagnostic workup were excluded from the study. Clinicoepidemiological and treatment-related data were collected from patient case file and health records available in the hospital database.

Patients were risk stratified into standard risk (SR), intermediate risk (IR), and high risk (HR) ("SR:" defined as prednisolone good response [PGR], age 1 year to younger than 6 years, initial white blood cell $[\mathrm{WBC}]<20 \times 10^{9} / \mathrm{L}$ and M1 [ $<5 \%$ blasts] or M2 [ $\geq 5 \%$ to $<25 \%$ blasts] marrow on day-15, and M1 marrow on day-33 [all criteria must be fulfilled]; "IR:" defined as PGR, age younger than 1 year or age 6 years or older and/or WBC $\geq 20 \times 10^{9} / \mathrm{L}$ and M1 or M2 marrow on day-15 and M1 marrow on day-33, or SR

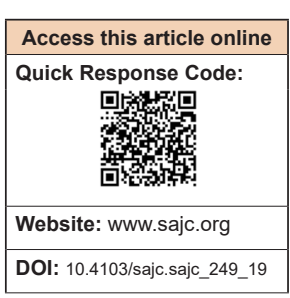

criteria but M3 [ $\geq 25 \%$ blasts] marrow on day- 15 and M1 marrow on day-33; and "HR:" defined as at least one of the following - prednisolone poor response, IR and M3 marrow on day-15, M2 or M3 marrow on day-33, t $(9 ; 22)$ [BCR-ABL], or $t(4 ; 11)$ [MLL-AF4]). ${ }^{[9]}$ All patients received initial treatment as per "SR" BFM 2002 protocol irrespective of the presence of baseline risk factors.

Day-8 hemogram after steroid use was used to evaluate early response ("Good response" was defined as absolute blast count $<1000 / \mathrm{mm}^{3}$ in peripheral blood). ${ }^{[9]}$ After the completion of induction Phase I therapy, day-33 bone marrow blast percentage was used to define "minimum residual disease" (MRD) status (negative MRD defined as blast percentage $<0.01 \%$ in bone marrow aspiration specimen by flow cytometry). ${ }^{[9]}$ Early response to treatment includes both day- 8 response and day-33 MRD. Treatment is intensified to "HR" protocol in patients who have not achieved negative MRD even after completion of both the induction phases of therapy. Early death was defined as death within 30 days of starting the treatment.

\section{Results}

A total of 73 patients of childhood ALL were registered at our institute during the study period. Of the 73 cases, 52 children were found to be eligible for inclusion in this study.

\section{Patient profile}

These included $36(69 \%)$ boys and $16(31 \%)$ girls, with male-to-female ratio was $2.2: 1$. The mean age for the entire cohort was 7.1 years (standard deviation $[\mathrm{SD}] \pm 4.7$; percentile [1-3]-[3.1-11]).

\section{Disease profile}

Of the 52 patients of childhood ALL, precursor B-cell ALL was the most common subtype accounting for $32(61 \%)$, B-cell type $11(21 \%)$, and T-cell $9(18 \%)$ of all cases [Table 1]. The most common presenting symptom was fever followed by bleeding and generalized weakness, which were present in $77 \%$, $38 \%$, and $26 \%$ of all patients, respectively.

This is an open access journal, and articles are distributed under the terms of the Creative Commons Attribution-NonCommercial-ShareAlike 4.0 License, which allows others to remix, tweak, and build upon the work non-commercially, as long as appropriate credit is given and the new creations are licensed under the identical terms.

For reprints contact: reprints@medknow.com

How to cite this article: Saikia BJ, Roy PS, Kumar G, Mishra RK, Sarma A Clinico-epidemiological features and response in childhood acute lymphoblastic leukemia at regional cancer center of Northeast India. South Asian J Cancer 2019;8:241-3. 
Regarding baseline hemogram, mean hemoglobin level was $6.9 \mathrm{~g} / \mathrm{dl}(\mathrm{SD} \pm 2.6$; percentile [1-3]-[5-8.8]), mean WBC count was $110 \times 10^{9} / \mathrm{L}\left(\mathrm{SD} \pm 150 \times 10^{9} / \mathrm{L}\right.$; percentile $[1-3]-[6022-161,500])$, and mean platelet count was $52.8 \times 10^{9} / \mathrm{L}\left(\mathrm{SD} \pm 36.5 \times 10^{9} / \mathrm{L}\right.$; percentile [1-3]-[19,250-68,750]).

Of the 52 patients, cytogenetic profile was available for 49 patients. Normal cytogenetics was seen in $39(80 \%)$ patients. Seven $(14 \%)$ patients had HR cytogenetics $(\mathrm{t}[9,22]$ in $3[43 \%] ; t[4,11]$ in $2[29 \%]$; and $t[1,19]$ and hypoploidy in 1 case [14\%] each). Three $(6 \%)$ patients had good risk cytogenetics (hyperploidy in two patients and $t(12,21)$ in

Table 1: Baseline demographic profile

\begin{tabular}{lc}
\hline Variables & $n(\%)$ \\
\hline Age $($ years $)(n=52)$ & $27(52)$ \\
$<1$ and $>5$ & $25(48)$ \\
$1-5$ & \\
Sex $(n=52)$ & $36(69)$ \\
$\quad$ Male & $16(31)$ \\
Female & \\
Subtype $(n=52)$ & $32(61)$ \\
Precursor B-cell & $11(21)$ \\
B-cell & $9(18)$ \\
T-cell & \\
Hb, g/dl $(n=52)$ & $44(85)$ \\
$<10$ & $8(15)$ \\
$\geq 10$ & \\
WBC count, $\times 10^{9} / \mathrm{L}(n=52)$ & $19(37)$ \\
$<20$ & $33(63)$ \\
$\geq 20$ & \\
Platelet count, $\times 10^{9} / \mathrm{L}(n=52)$ & $42(81)$ \\
$<100$ & $10(19)$ \\
$\geq 100$ & \\
Cytogenetics $(n=49)$ & $7(14)$ \\
HR & $39(80)$ \\
Normal & $3(6)$ \\
Good risk &
\end{tabular}

$\mathrm{HR}=$ High risk, $\mathrm{Hb}=$ Hemoglobin, $\mathrm{WBC}=$ White blood cell one patient). Cytogenetics report could not be retrieved for three patients [Table 1]. Baseline cerebrospinal fluid (CSF) cytology was performed in 49 of 52 children and was negative in all cases. CSF cytology was not done in three patients at baseline (low platelet count $<10 \times 10^{9} / \mathrm{L}$ ).

\section{Treatment response}

Early deaths were seen in $11(21 \%)$ of 52 children. The most common cause was bleeding which accounts for early death in 7 cases (64\%) and tumor lysis syndrome and febrile neutropenia in 2 cases $(18 \%)$ each. Mean number of days from start of treatment to early deaths was 5.5 days (range 3-13 days).

Early response to treatment was assessed with day- 8 peripheral blood blast count in 45 of 52 patients (seven children died before completing day-8 steroid) and day-33 MRD assessed in 41 of 52 patient ( 11 children died before completing Phase I of induction chemotherapy). Of 45 children, 8 (18\%) children did not achieve "good response" to steroid and $11(27 \%)$ children had positive MRD after completing Phase I induction therapy [Table 2].

On further analysis, it was found that male sex had poor early responses (poor day- 8 response in 8 patients [26\%] $[P=0.04$; confidence interval (CI) 95\%] and positive day-33 MRD in 11 [39\%] patients [ $P=0.007$; CI 95\%]) [Table 2]. The presence of HR cytogenetics was also found to be associated with poor day-8 response in $4(57 \%)$ patients $(P=0.01$; CI $95 \%)$ and positive day-33 MRD in $4(66 \%)$ patients $(P=0.04$; CI $95 \%$ ). Contrary to this, age $<1$ and $>5$ years and higher baseline WBC counts $\geq 20 \times 10^{9} / \mathrm{L}$ were not seen to be significantly associated with poor early responses. Regarding subtypes of ALL, although precursor B-cell and T-cell ALL were found to have better day- 8 response as compared to B-cell type; however, the association was not found to be statistically significant $(P=0.07$; CI 95\%).

\section{Discussion}

In this study, we found the mean age of children with ALL to be 7.1 years with male preponderance. The proportion of

Table 2: Factors associated with poor early responses

\begin{tabular}{|c|c|c|c|c|}
\hline \multirow[t]{2}{*}{ Variables } & \multicolumn{4}{|c|}{ Poor early response } \\
\hline & $\begin{array}{c}\text { Day-8 peripheral blood blast } \\
\text { count } \geq 1000 / \mathrm{mm}^{3}(n=8 / 45)\end{array}$ & $P$ & $\begin{array}{l}\text { Day-33 MRD (bone marrow } \\
\text { blast } \geq 0.01 \%)(n=11 / 41)\end{array}$ & $P$ \\
\hline \multicolumn{5}{|l|}{ Age (years) } \\
\hline$<1$ and $>5$ & 2 & 0.17 & 4 & 0.43 \\
\hline $1-5$ & 6 & & 7 & \\
\hline \multicolumn{5}{|l|}{ Sex } \\
\hline Male & 8 & 0.03 & 11 & 0.008 \\
\hline Female & 0 & & 0 & \\
\hline \multicolumn{5}{|l|}{ WBC count, $\times 10^{9} / \mathrm{L}$} \\
\hline$\geq 20$ & 7 & 0.08 & 9 & 0.09 \\
\hline$<20$ & 1 & & 2 & \\
\hline \multicolumn{5}{|l|}{ Subtype } \\
\hline Precursor B-cell & 3 & 0.07 & 8 & 0.83 \\
\hline B-cell & 4 & & 2 & \\
\hline T-cell & 1 & & 1 & \\
\hline \multicolumn{5}{|l|}{ Cytogenetics } \\
\hline HR & 4 & 0.01 & 4 & 0.04 \\
\hline Normal & 4 & & 7 & \\
\hline Good risk & 0 & & 0 & \\
\hline \multicolumn{5}{|c|}{ MRD=Minimum residual disease, $\mathrm{HR}=$ High risk, $\mathrm{WBC}=$ White blood cell } \\
\hline 242 & & Asiar & ncer $\bullet$ Volume $8 \bullet$ Issue $4 \bullet 0$ & ber 201 \\
\hline
\end{tabular}


children with baseline WBC count $\geq 20 \times 10^{9} / \mathrm{L}$ was $33(63 \%)$. Precursor B-cell was the most common subtype and children with T-cell subtype were 7 (18\%) of all cases. Seven (14\%) of 49 cases had HR cytogenetics, of which $t(9,22)$ was most commonly present in $3(43 \%)$ of seven children. The number of early deaths was 11 (21\%), of which bleeding was the most common cause. Regarding early response to treatment, 8 (18\%) of all evaluable children had poor day- 8 response to steroids and $11(27 \%)$ children had positive day-33 MRD. Male sex and HR cytogenetics were significantly associated with poor early responses. B-cell subtype was associated with poor early responses as compared to precursor B-cell and T-cell subtype, but the difference was not statistically significant.

Age at presentation and male sex predominance in our study were found to be similar when we compared the results with other Indian studies. ${ }^{[10-12]}$ The proportion of T-cell subtype was lower (18\% in our study) than average of $30 \%-50 \%$ in different Indian studies. ${ }^{[10,13]}$ More children presented with higher baseline WBC count ( $65 \%$ in our study) than average of $30 \%-40 \%$ in other studies. ${ }^{[10,14,15]}$ We found higher proportions of BCR-ABL positivity (43\% vs. $8.3 \%$ from a South Indian study). ${ }^{[16]}$ We did not found any CNS-positive disease at baseline, as compared to $3 \%-6 \%$ positivity reported in various Indian studies. ${ }^{[12,17,18]}$ We also found higher early deaths in our study (21\% vs. $10 \%-12 \%$ ) compared to other studies from India. ${ }^{[17,18]}$ Regarding early treatment response rates, we found negative day-33 MRD as $73 \%$ when compared with morphological complete response (CR) of 83\%-94\% reported by different studies from India. ${ }^{[10,17-19]}$ It is inappropriate to compare day-33 MRD with morphologic CR, as bone marrow assessment for MRD was not done in majority of those studies which were conducted before the year 2010. Reason for poor early response seen in our study is due to higher proportion of children with HR factors.

Poor outcomes of treatment in middle- to low-income countries are mainly attributed to frequent treatment abandonment, more early toxic deaths, and higher relapse rates as compared to high income countries..$^{[8,20]}$

\section{Conclusion}

ALL is a common childhood malignancy with high cure rates. However, poor socioeconomic status in addition to the presence of higher proportions of disease-related risk factors in children with ALL leads to poor outcome in this part of the country.

\section{Acknowledgment}

Authors are grateful to the Hospital-Based Cancer Registry (HBCR) of Dr. B Borooah Cancer Institute, Guwahati, Assam, for providing the data.

Financial support and sponsorship

Nil.

\section{Conflicts of interest}

There are no conflicts of interest.

\section{References}

1. Magrath I, Steliarova-Foucher E, Epelman S, Ribeiro RC, Harif M, Li CK, et al. Paediatric cancer in low-income and middle-income countries. Lancet Oncol 2013; 14:e 104-16.

2. Ferlay J, Shin HR, Bray F, Forman D, Mathers C, Parkin DM, et al. Estimates of worldwide burden of cancer in 2008: GLOBOCAN 2008. Int J Cancer 2010; 127:2893-917.

3. Dinand V, Arya LS. Epidemiology of childhood Hodgkins disease: Is it different in developing countries? Indian Pediatr 2006;43:141-7.

4. Yaris N, Mandiracioglu A, Buyukpamukcu M. Childhood cancer in developing countries. Pediatr Hematol Oncol 2014;21:237-53.

5. Arora RS, Eden TO, Kapoor G. Epidemiology of childhood cancer in India. Indian J Cancer 2009;46:264-73.

6. National Cancer Registry Programme 2013. Consolidated Report of Hospital Based Cancer Registries: 2007-2011. Cancer in Childhood. Bangalore: National Centre for Disease Informatics and Research-Indian Council of Medical Research; 2013.

7. Asthana S, Labani S, Mehrana S, Bakhshi S. Incidence of childhood leukemia and lymphoma in India. Pediatr Hematol Oncol J 2018;3:115-20.

8. Hazarika M, Krishnatreya M, Bhuyan C, Saikia BJ, Kataki AC, Roy PS, et al. Overview of childhood cancers at a regional cancer centre in North-East India. Asian Pac J Cancer Prev 2014; 15:7817-9.

9. Stary J, Zimmermann M, Campbell M, Castillo L, Dibar E, Donska S, et al. Intensive chemotherapy for childhood acute lymphoblastic leukemia: Results of the randomized intercontinental trial ALL IC-BFM 2002. J Clin Oncol 2013;48:6522.

10. Magrath I, Shanta V, Advani S, Adde M, Arya LS, Banavali S, et al. Treatment of acute lymphoblastic leukaemia in countries with limited resources; lessons from use of a single protocol in India over a twenty year period [corrected]. Eur J Cancer 2005;41:1570-83.

11. Kulkarni KP, Arora RS, Marwaha RK. Survival outcome of childhood acute lymphoblastic leukemia in India: A resource-limited perspective of more than 40 years. J Pediatr Hematol Oncol 2011;33:475-9.

12. Bajel A, George B, Mathews V, Viswabandya A, Kavitha ML, Srivastava A, et al. Treatment of children with acute lymphoblastic leukemia in India using a BFM protocol. Pediatr Blood Cancer 2008;51:621-5.

13. Mukhopadhyay A, Gangopadhyay S, Dasgupta S, Paul S, Mukhopadhyay S, Ray UK. Surveillance and expected outcome of acute lymphoblastic leukemia in children and adolescents: An experience from Eastern India. Indian J Med Paediatr Oncol 2013;34:280-2.

14. Gupta A, Kapoor G, Jain S, Bajpai R. Absolute lymphocyte count recovery independently predicts outcome in childhood acute lymphoblastic leukemia: Experience from a tertiary care cancer center of a developing country. J Pediatr Hematol Oncol 2015;37: 143-9.

15. Radhakrishnan V, Gupta S, Ganesan P, Rajendranath R, Ganesan TS, Rajalekshmy KR, et al. Acute lymphoblastic leukemia: A single center experience with Berlin, Frankfurt, and Munster-95 protocol. Indian J Med Paediatr Oncol 2015;36:261-4.

16. Sugapriya D, Preethi S, Shanthi P, Chandra N, Jeyaraman G, Sachdanandam $\mathrm{P}$, et al. BCR-ABL translocation in pediatric acute lymphoblastic leukemia in Southern India. Indian J Hematol Blood Transfus 2012;28:37-41.

17. Arya LS, Kotikanyadanam SP, Bhargava M, Saxena R, Sazawal S, Bakhshi S, et al. Pattern of relapse in childhood ALL: Challenges and lessons from a uniform treatment protocol. J Pediatr Hematol Oncol 2010;32:370-5.

18. Kulkarni KP, Marwaha RK, Trehan A, Bansal D. Survival outcome in childhood ALL: Experience from a tertiary care centre in North India. Pediatr Blood Cancer 2009;53: 168-73.

19. Varghese B, Joobomary AA, Savida P. Five-year survival rate and the factors for risk-directed therapy in acute lymphoblastic leukemia. J Med Paediatr Oncol 2018;39:301-6.

20. Pui CH, Yang JJ, Hunger SP, Pieters R, Schrappe M, Biondi A, et al. Childhood acute lymphoblastic leukemia: Progress through collaboration. J Clin Oncol 2015;33:2938-48. 